\title{
Evaluation of Analytical Performance in Clinical Biochemistry Laboratory in India Using Six Sigma Methodology
}

\author{
Nishtha Wadhwa ${ }^{1}$, Anitha Devanath ${ }^{2}$
}

\begin{abstract}
Introduction: Internal and external quality controls (QCs) used in the laboratory are effective in detecting analytical errors. However, they cannot quantify the number of errors. Six sigma can be used to objectively evaluate the performance of analytical methods. Hence, we have evaluated the analytical performance of 19 parameters using six sigma methodology.

Materials and methods: Quality control data were collected over a period of 6 months_from January to June 2016 —and sigma metric was calculated. Parameters showing sigma metrics of $\leq 3$ were further analyzed between July and September 2016 by applying the suggested rules from Unity Real Time (URT) software.

Results: Gamma-glutamyl transferase (GGT) Level (L) 2 showed the highest value of sigma (13.22). Total bilirubin was found to have the highest sigma values at both control levels (7.15 and 9.49 at $L 1$ and $L 2$, respectively). Sigma value of $\geq 4$ was observed across all control levels for anti-TPO, CK-MB, potassium, PSA, and TSH. L1 of alpha feto protein (AFP) and L2 of Troponin I had sigma value of $\leq 3$. We have obtained sigma value of $\leq 3$ for all levels of remaining analytes. Among these, L1 of AFP showed a significant improvement in sigma after the application of suggested rules (2.5 to 9.3). Conclusion: The sigma value for a test is a good indication of its process capability because it considers both bias and imprecision. Unfortunately, most clinical laboratory tests are below six sigma processes. It is imperative to implement appropriate QC strategies for the judicious use of quality control.
\end{abstract}

Keywords: Quality control, Root cause analysis, Six sigma, Total error, Westgard rules.

Indian Journal of Medical Biochemistry (2020): 10.5005/jp-journals-10054-0131

\section{INTRODUCTION}

Quality control (QC) is used in medical laboratory to monitor the performance of analytical process. ${ }^{1}$ Quality in the lab can be evaluated by using a combination of internal quality control (IQC) and proficiency testing (PT).

A combination of IQC and PT program is effective in detecting analytical errors. However, the number of errors (or defects) in the laboratory cannot be quantified by reviewing IQC and PT programs. The quantifiable parameters obtained from IQC/PT programs can be used to calculate sigma metrics which would provide a quantifiable measure of errors/defects in the laboratory. The advantage of sigma metric is that in one number, it neatly summarizes a characteristic of multiple key analytical performance characteristics. ${ }^{2}$

In a collective opinion paper on findings of the 2010 convocation of experts on laboratory quality, Cooper et al. suggested the use of sigma to decide $\mathrm{QC}$ frequency. They suggested that the tests should be divided into three groups as follows: ${ }^{2}$

- $>6 \sigma$ (excellent tests) —evaluate with one QC per day (alternating levels between days) and a 1:3.5 s rule.

- $\quad 4 \sigma-6 \sigma$ (suited for purpose) — evaluate with two levels of QC per day and the 1:2.5 seconds rule.

- $\quad 3 \sigma-4 \sigma$ (poor performers) - use a combination of rules with two levels of QC twice per day.

- $\quad<3 \sigma$ (problems) - maximum QC, three levels, three times a day. Through sigma metrics, it is easy to identify high-risk and lowrisk test methods. ${ }^{3}$

To design the right statistical QC procedure, Westgard suggested the use of Westgard sigma rules as shown in Figure $1 .^{4}$

In resource-poor settings, it becomes imperative to implement measures that avoid wastage while maintaining the desired level
${ }^{1}$ Department of Biochemistry, Sri Aurobindo Medical College and Hospital, Indore, Madhya Pradesh, India

${ }^{2}$ Department of Biochemistry, St. Johns Medical College, Bengaluru, Karnataka, India

Corresponding Author: NishthaWadhwa, Department of Biochemistry, Sri Aurobindo Medical College and Hospital, Indore, Madhya Pradesh, India, Phone:+91 9008565760, e-mail: nishthawadhwa@gmail.com

How to cite this article: Wadhwa N, Devanath A. Evaluation of Analytical Performance in Clinical Biochemistry Laboratory in India Using Six Sigma Methodology. Indian J Med Biochem 2020;24(1): 19-24.

Source of support: Nil

Conflict of interest: None

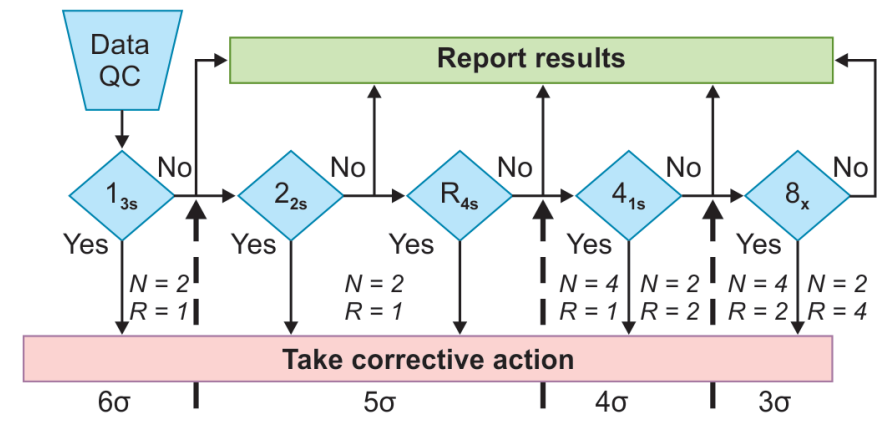

Fig. 1: Westgard sigma rules for 2 levels of control materials

(0) The Author(s). 2020 Open Access This article is distributed under the terms of the Creative Commons Attribution 4.0 International License (https://creativecommons. org/licenses/by-nc/4.0/), which permits unrestricted use, distribution, and non-commercial reproduction in any medium, provided you give appropriate credit to the original author(s) and the source, provide a link to the Creative Commons license, and indicate if changes were made. The Creative Commons Public Domain Dedication waiver (http://creativecommons.org/publicdomain/zero/1.0/) applies to the data made available in this article, unless otherwise stated. 
of quality. Hence, practising the use sigma metric to design QC can prove useful in our setting.

In this study, the analytical performance of the following tests done in clinical biochemistry laboratory was evaluated using six sigma methodology: alpha feto protein (AFP), ALP, anti-TPO, calcium, chloride, CK-MB, creatinine, ferritin, folate, free T4, Gammaglutamyl transferase (GGT), magnesium, potassium, PSA, sodium, total bilirubin, troponin I, TSH, vitamin B12, and for analytes having sigma metric of $<3$ were compared before and after the application of suggested rules.

\section{Materials and Methods}

The study was performed at Clinical Biochemistry Laboratory of St. John's Medical College Hospital, Bengaluru, India. Data were collected over a period of 9 months from January to September 2016 from Unity Real Time (URT) software, Bio-Rad Laboratories, Inc. IQC data of all levels that were accepted for analytical run in the laboratory from January to September 2016 were included in the study. Any data points that have been rejected or excluded by the laboratory due to being flagged with errors during QC run, gross mistakes while preparing QC (pipetting errors) that were not accepted for analytical runs, QC runs just before or at the time of equipment breakdown, and multirule criteria applied for QC run were excluded from the study. Total 19 analytes were chosen for the study.

Table 1 shows the method of analysis and the instruments used to analyze the respective analyte.

Sigma metric was calculated for all the analytes for the period of January-June 2016. The analytes which showed sigma metric of $<3$ were further analyzed during the period of July-September 2016 after the application of rules as suggested by URT.

The study was approved by Institutional Ethical Committee.

\section{Method of Calculating Sigma Metric}

The sigma metrics for the various analytes were calculated by the following formula:

$$
\text { Sigma }(\sigma)=\text { TEa }- \text { Bias } / \text { CV }
$$

where Tea is the total allowable error and CV is the coefficient of variation.

TEa values of various parameters were taken from the biological variation database by Dr Carmen Ricos et al. available at www. westgard.com. ${ }^{5}$

CV was determined from the calculated laboratory mean and calculated standard deviation procured from the IQC data.

$$
\text { CV }(\%)=(\text { Standard deviation / Laboratory mean }) \times 100
$$

Peer mean was obtained from URT software and bias was calculated by using the formula

$$
\text { Bias }(\%)=(\text { Our mean }- \text { Peer mean } / \text { Peer mean }) \times 100
$$

\section{Statistical Software}

The data were entered and analyzed on Microsoft Excel Version 2016.

\section{Results}

The units, QC levels, lab mean, standard deviation (SD), CV, peer mean, and bias for the analytes for the period of January-June

\begin{tabular}{|c|c|c|}
\hline Analyte & Instrument & Method \\
\hline AFP & Siemens ADVIA Centaur XP & Chemiluminescence \\
\hline ALP & Siemens Dimension EXL & $\begin{array}{l}\text { Modified Bower's and } \\
\text { McComb method/ } \\
\text { modified Rej }\end{array}$ \\
\hline Anti-TPO & Siemens ADVIA Centaur XP & Chemiluminescence \\
\hline Calcium & Siemens Dimension EXL & $\begin{array}{l}\text { Modified } o- \\
\text { cresolphthalein } \\
\text { complexone }\end{array}$ \\
\hline Chloride & Siemens Dimension EXL & ISE, indirect \\
\hline CK-MB & Siemens ADVIA Centaur XP & Chemiluminescence \\
\hline Creatinine & Siemens Dimension EXL & $\begin{array}{l}\text { Alkaline picrate- } \\
\text { kinetic }\end{array}$ \\
\hline Ferritin & Siemens ADVIA Centaur XP & Chemiluminescence \\
\hline Folate & Siemens ADVIA Centaur XP & Chemiluminescence \\
\hline Free T4 & Siemens ADVIA Centaur XP & Chemiluminescence \\
\hline GGT & Siemens Dimension EXL & $\begin{array}{l}\text { G-glutamyl-carboxy- } \\
\text { nitroanilide }\end{array}$ \\
\hline Magnesium & Siemens Dimension EXL & Methylthymol blue \\
\hline Potassium & Siemens Dimension EXL & ISE, indirect \\
\hline PSA & Roche cobas 6000 & $\begin{array}{l}\text { Electrochemilumi- } \\
\text { nescence }\end{array}$ \\
\hline Sodium & Siemens Dimension EXL & ISE, indirect \\
\hline Total bilirubin & Siemens Dimension EXL & $\begin{array}{l}\text { Modified Jendrassik } \\
\text { and Grof method. }\end{array}$ \\
\hline Troponin I & Siemens ADVIA Centaur XP & Chemiluminescence \\
\hline TSH & Siemens ADVIA Centaur XP & Chemiluminescence \\
\hline Vitamin B12 & Siemens ADVIA Centaur XP & Chemiluminescence \\
\hline
\end{tabular}
2016 are shown in Table 2.
Table 1: List of analytes, instrument used, and the method of analysis

Sigma metric was calculated for the analytes for the period of January-June 2016 and is presented in Table 3 along with the TEa targets for the analytes.

Analytes having sigma metric of $<3$ were analyzed in the period of July-September 2016 by applying the suggested rules from URT.

Table 4 lists the analytes that were chosen for further analysis, and existing $Q C$ rejection rules and rejection rules suggested by URT software are also shown.

Among 19 analyzes performed, 8 showed improvement in sigma value after the application of suggested rules. Table 5 depicts the analytes and levels that showed an improvement in sigma value after the application of suggested rules.

AFP Level 1 (Figs 2 and 3) showed sigma metric of $\geq 3$ after the application of suggested rules.

The following analytes also showed an improvement in sigma metric but showed sigma performance $\leq 3$ even after the application of suggested rules: calcium L2, chloride L1 and L2, magnesium $L 1$ and $L 2$, sodium $L 1$ and $L 2$.

Method decision charts for calcium L1 and L2 are presented in Figures 4 to 7 . We can see from the figures that calcium has not shown much improvement on the application of suggested rules. We can also note that the TEa target is very narrow.

Table 6 shows the list of analytes that did not show any improvement after the application of suggested rules.

\section{Discussion}

It is generally believed that if a laboratory follows the regulatory requirements, its performance is good. However, this is not always true. ${ }^{6}$ 
Six Sigma Evaluation

Table 2: Lab mean, SD, CV, peer mean, and bias for the period of January-June 2016 ( $N=$ number of data points)

\begin{tabular}{|c|c|c|c|c|c|c|c|}
\hline Analyte & Unit & Level & Lab mean $(N)$ & $S D$ & $C V$ & Peer mean $(N)$ & Bias \\
\hline \multirow[t]{2}{*}{ AFP } & $\mathrm{ng} / \mathrm{mL}$ & 1 & $10.63(41)$ & 0.61 & 5.72 & $11.51(6,081)$ & -7.61 \\
\hline & & 2 & $91.48(26)$ & 3.39 & 3.7 & $93.16(4,879)$ & -1.8 \\
\hline \multirow[t]{2}{*}{ ALP } & $\mathrm{U} / \mathrm{L}$ & 1 & $100.96(424)$ & 2.64 & 2.61 & $98.58(7,453)$ & 2.42 \\
\hline & & 2 & 399.81 (443) & 8.44 & 2.11 & $397.68(7,493)$ & 0.54 \\
\hline \multirow[t]{2}{*}{ Anti-TPO } & $\mathrm{U} / \mathrm{mL}$ & 1 & 107.07 (119) & 9.36 & 8.74 & $113.04(696)$ & -5.29 \\
\hline & & 2 & $260.79(38)$ & 12.25 & 4.7 & $274.34(316)$ & -4.94 \\
\hline \multirow[t]{2}{*}{ Calcium } & $\mathrm{mg} / \mathrm{dL}$ & 1 & $8.800(222)$ & 0.16 & 1.81 & $8.808(9,716)$ & -0.01 \\
\hline & & 2 & $11.71(242)$ & 0.24 & 2.08 & $11.74(9,424)$ & -0.27 \\
\hline \multirow[t]{2}{*}{ Chloride } & $\mathrm{mEq} / \mathrm{L}$ & 1 & $114.90(440)$ & 2.23 & 1.94 & $115.71(5,593)$ & -0.7 \\
\hline & & 2 & $97.02(443)$ & 1.89 & 1.95 & $97.68(5,562)$ & -0.67 \\
\hline \multirow[t]{2}{*}{ CK-MB } & $\mathrm{ng} / \mathrm{mL}$ & 1 & $3.95(70)$ & 0.19 & 4.92 & $3.68(3,456)$ & 7.4 \\
\hline & & 2 & $13.67(91)$ & 0.65 & 4.75 & $12.94(4,448)$ & 5.6 \\
\hline \multirow[t]{2}{*}{ Creatinine } & $\mathrm{mg} / \mathrm{dL}$ & 1 & $2.84(137)$ & 0.07 & 2.34 & $2.80(4,278)$ & 1.31 \\
\hline & & 2 & $6.17(143)$ & 0.14 & 2.31 & $6.21(4,284)$ & -0.71 \\
\hline \multirow[t]{3}{*}{ Ferritin } & $\mathrm{ng} / \mathrm{mL}$ & 1 & $58.74(102)$ & 3.19 & 5.42 & $58.1(16,351)$ & 1.09 \\
\hline & & 2 & 139.52 (99) & 11.42 & 8.18 & $141.99(11,991)$ & -1.74 \\
\hline & & 3 & 381.21 (130) & 35.68 & 9.36 & $383.07(15,448)$ & -0.48 \\
\hline \multirow[t]{3}{*}{ Folate } & $\mathrm{ng} / \mathrm{mL}$ & 1 & $2.37(41)$ & 0.43 & 18.09 & $2.49(12,957)$ & -4.82 \\
\hline & & 2 & $7.07(50)$ & 0.9 & 12.79 & $7.35(11,237)$ & -3.82 \\
\hline & & 3 & $10.76(70)$ & 1.25 & 11.64 & $11.48(11,400)$ & -6.32 \\
\hline \multirow[t]{3}{*}{ Free T4 } & $\mathrm{ng} / \mathrm{dL}$ & 1 & $0.71(99)$ & 0.07 & 9.49 & $0.69(23,778)$ & 2.82 \\
\hline & & 2 & $1.94(100)$ & 0.13 & 6.7 & $1.92(21,777)$ & 0.84 \\
\hline & & 3 & 3.13 (129) & 0.26 & 8.35 & $3.08(20,118)$ & 1.58 \\
\hline \multirow[t]{2}{*}{ GGT } & $\mathrm{U} / \mathrm{L}$ & 1 & 67.49 (426) & 1.72 & 2.55 & $62.35(152)$ & 8.24 \\
\hline & & 2 & $176.36(433)$ & 2.54 & 1.44 & $171.16(155)$ & 3.04 \\
\hline \multirow[t]{2}{*}{ Magnesium } & $\mathrm{mg} / \mathrm{dL}$ & 1 & $2.04(210)$ & 0.06 & 3.16 & $2.07(6,083)$ & -1.42 \\
\hline & & 2 & $4.68(227)$ & 0.12 & 2.63 & $4.75(6,010)$ & -1.31 \\
\hline \multirow[t]{2}{*}{ Potassium } & $\mathrm{mEq} / \mathrm{L}$ & 1 & $3.78(445)$ & 0.04 & 1 & $3.81(5,447)$ & -0.85 \\
\hline & & 2 & $6.11(450)$ & 0.07 & 1.15 & $6.15(5,477)$ & -0.68 \\
\hline \multirow[t]{2}{*}{ PSA } & $\mathrm{ng} / \mathrm{mL}$ & 1 & $0.180(36)$ & 0.01 & 5.24 & $0.1755(6,534)$ & 2.52 \\
\hline & & 2 & $4.39(26)$ & 0.09 & 2.04 & $3.99(5,161)$ & 9.8 \\
\hline \multirow[t]{2}{*}{ Sodium } & $\mathrm{mEq} / \mathrm{L}$ & 1 & $139.60(454)$ & 1.36 & 0.98 & $140.67(5,577)$ & -0.76 \\
\hline & & 2 & $125.63(447)$ & 1.24 & 0.98 & $126.65(5,562)$ & -0.81 \\
\hline \multirow[t]{2}{*}{ Total bilirubin } & $\mathrm{mg} / \mathrm{dL}$ & 1 & $0.92(417)$ & 0.03 & 3.54 & $0.93(4,909)$ & -1.63 \\
\hline & & 2 & $4.36(434)$ & 0.12 & 2.79 & $4.38(4,904)$ & -0.41 \\
\hline \multirow[t]{2}{*}{ Troponin I } & $\mathrm{ng} / \mathrm{mL}$ & 1 & $0.10(64)$ & 0.01 & 6.84 & $0.096(3,484)$ & 3.91 \\
\hline & & 2 & $4.13(93)$ & 0.37 & 9 & $5.33(2,382)$ & -22.59 \\
\hline \multirow[t]{3}{*}{ TSH } & $\mu \mathrm{IU} / \mathrm{mL}$ & 1 & $0.36(154)$ & 0.01 & 3.55 & $0.37(23,291)$ & -2.53 \\
\hline & & 2 & $5.1(147)$ & 0.18 & 3.6 & $5.25(22,066)$ & -2.93 \\
\hline & & 3 & $29.63(196)$ & 1.05 & 3.56 & $30.55(19,858)$ & -3.02 \\
\hline \multirow[t]{3}{*}{ Vitamin B12 } & $\mathrm{pg} / \mathrm{mL}$ & 1 & 421.66 (107) & 30.21 & 7.17 & $410.71(16,149)$ & 2.66 \\
\hline & & 2 & $543.21(101)$ & 38.98 & 7.18 & $529.35(12,925)$ & 2.62 \\
\hline & & 3 & 849.06 (126) & 40.86 & 4.81 & $848.01(14,083)$ & 0.12 \\
\hline
\end{tabular}

There is still a wide scope of improvement in the quality of laboratory processes, and there is an utmost need to follow the right strategies for doing so to avoid wastage and delivery of wrong results.

A systematic approach is needed to reliably detect clinically significant analytic errors that are beyond allowable inherent errors. This justifies the main objective of the sigma metrics analysis; first, to detect the errors that are more than allowed and then to minimize the identified defects. ${ }^{7-10}$
In this study, we have carried out sigma metric analysis of analytical performance. Analysis was straightforward, as the information of CV\% and bias was readily available with laboratory QC records.

Unity Real Time software suggests rules for each analyte based on its performance. However, there is a general norm to use same rules for all analytes. This may lead to high false rejection in a process with high sigma and low error detection in process with poor sigma. ${ }^{6}$ 
Table 3: TEa targets and sigma metric for analytes for the period of January-June 2016

\begin{tabular}{|c|c|c|c|}
\hline Analyte & Level & $T E a$ & Sigma \\
\hline \multirow[t]{2}{*}{ AFP } & 1 & 21.9 & 2.5 \\
\hline & 2 & 21.9 & 5.43 \\
\hline \multirow[t]{2}{*}{ ALP } & 1 & 12.04 & 3.66 \\
\hline & 2 & 12.04 & 5.43 \\
\hline \multirow[t]{2}{*}{ Anti-TPO } & 1 & 46.2 & 4.68 \\
\hline & 2 & 46.2 & 8.78 \\
\hline \multirow[t]{2}{*}{ Calcium } & 1 & 2.55 & 1.41 \\
\hline & 2 & 2.55 & 1.1 \\
\hline \multirow[t]{2}{*}{ Chloride } & 1 & 1.5 & 0.4 \\
\hline & 2 & 1.5 & 0.41 \\
\hline \multirow[t]{2}{*}{ CK-MB } & 1 & 30.06 & 4.62 \\
\hline & 2 & 30.06 & 5.16 \\
\hline \multirow[t]{2}{*}{ Creatinine } & 1 & 8.87 & 3.25 \\
\hline & 2 & 8.87 & 3.55 \\
\hline \multirow[t]{3}{*}{ Ferritin } & 1 & 16.9 & 2.91 \\
\hline & 2 & 16.9 & 1.85 \\
\hline & 3 & 16.9 & 1.75 \\
\hline \multirow[t]{3}{*}{ Folate } & 1 & 39 & 1.89 \\
\hline & 2 & 39 & 2.75 \\
\hline & 3 & 39 & 2.81 \\
\hline \multirow[t]{3}{*}{ Free T4 } & 1 & 8.05 & 0.55 \\
\hline & 2 & 8.05 & 1.08 \\
\hline & 3 & 8.05 & 0.78 \\
\hline \multirow[t]{2}{*}{ GGT } & 1 & 22.1 & 5.43 \\
\hline & 2 & 22.1 & 13.22 \\
\hline \multirow[t]{2}{*}{ Magnesium } & 1 & 4.81 & 1.07 \\
\hline & 2 & 4.81 & 1.33 \\
\hline \multirow[t]{2}{*}{ Potassium } & 1 & 5.61 & 4.76 \\
\hline & 2 & 5.61 & 4.29 \\
\hline \multirow[t]{2}{*}{ PSA } & 1 & 33.6 & 5.93 \\
\hline & 2 & 33.6 & 11.67 \\
\hline \multirow[t]{2}{*}{ Sodium } & 1 & 0.73 & -0.04 \\
\hline & 2 & 0.73 & -0.08 \\
\hline \multirow[t]{2}{*}{ Total bilirubin } & 1 & 26.9 & 7.15 \\
\hline & 2 & 26.9 & 9.49 \\
\hline \multirow[t]{2}{*}{ Troponin I } & 1 & 27.9 & 3.51 \\
\hline & 2 & 27.9 & 0.59 \\
\hline \multirow[t]{3}{*}{ TSH } & 1 & 23.7 & 5.96 \\
\hline & 2 & 23.7 & 5.78 \\
\hline & 3 & 23.7 & 5.81 \\
\hline \multirow[t]{3}{*}{ Vitamin B12 } & 1 & 30 & 3.81 \\
\hline & 2 & 30 & 3.82 \\
\hline & 3 & 30 & 6.21 \\
\hline
\end{tabular}

It is suggested that for a process with sigma $\geq 6$, to avoid false rejections, control limits should be relaxed up to 3.5 SD with $N$ (number of controls to be run per day) $=2$; for a five sigma process, 3.0 SD control limits with $N=2$ have to be used; for a four sigma process, 2.5 SD control limits or a multirule procedure with $N=4$ have to be used; for a three sigma process, multirule procedures with $\mathrm{N}$ of 6 or 8 have to be used. For less than three sigma, method
Table 4: Analytes that showed sigma $\leq 3$ arranged in ascending order of sigma

\begin{tabular}{llcll}
\hline Analyte & Level & Sigma & Existing rules & Suggested rules \\
\hline Sodium & 2 & -0.08 & $13 s, 22 s, R 4 s$ & $13 s, 22 s, R 4 s, 41 s, 8 x$ \\
Sodium & 1 & -0.04 & $13 s, 22 s, R 4 s$ & $13 s, 22 s, R 4 s, 41 s, 8 x$ \\
Chloride & 1 & 0.4 & $13 s, 22 s, R 4 s$ & $13 s, 22 s, R 4 s, 41 s, 8 x$ \\
Chloride & 2 & 0.41 & $13 s, 22 s, R 4 s$ & $13 s, 22 s, R 4 s, 41 s, 8 x$ \\
Free T4 & 1 & 0.55 & $13 s, 22 s, R 4 s$ & $13 s, 22 s, R 4 s, 31 s, 8 x$ \\
Troponin I & 2 & 0.59 & $13 s, 22 s, R 4 s$ & $13 s, 22 s, R 4 s$ \\
Free T4 & 3 & 0.78 & $13 s, 22 s, R 4 s$ & $13 s, 22 s, R 4 s$ \\
Magnesium & 1 & 1.07 & $13 s, 22 s, R 4 s$ & $13 s, 22 s, R 4 s, 41 s, 8 x$ \\
Free T4 & 2 & 1.08 & $13 s, 22 s, R 4 s$ & $13 s, 22 s, R 4 s$ \\
Calcium & 2 & 1.1 & $13 s, 22 s, R 4 s$ & $13 s, 22 s, R 4 s, 41 s, 8 x$ \\
Magnesium & 2 & 1.33 & $13 s, 22 s, R 4 s$ & $13 s, 22 s, R 4 s, 41 s, 8 x$ \\
Calcium & 1 & 1.41 & $13 s, 22 s, R 4 s$ & $13 s, 22 s, R 4 s, 41 s, 8 x$ \\
Ferritin & 3 & 1.75 & $13 s, 22 s, R 4 s$ & $13 s, 22 s, R 4 s$ \\
Ferritin & 2 & 1.85 & $13 s, 22 s, R 4 s$ & $13 s, 22 s, R 4 s$ \\
Folate & 1 & 1.89 & $13 s, 22 s, R 4 s$ & $13 s, 22 s, R 4 s$ \\
AFP & 1 & 2.5 & $13 s, 22 s, R 4 s$ & $12 s, 13 s, 22 s, R 4 s$ \\
Folate & 2 & 2.75 & $13 s, 22 s, R 4 s$ & $13 s, 22 s, R 4 s$ \\
Folate & 3 & 2.81 & $13 s, 22 s, R 4 s$ & $13 s, 22 s, R 4 s$ \\
\hline
\end{tabular}

Table 5: Analytes that showed improvement in sigma after the application of suggested rules

\begin{tabular}{llcl}
\hline Analyte & Level & $\begin{array}{l}\text { Sigma before } \\
\text { application of } \\
\text { suggested rules }\end{array}$ & $\begin{array}{l}\text { Sigma after } \\
\text { application of } \\
\text { suggested rules }\end{array}$ \\
\hline AFP & 1 & 2.5 & 9.3 \\
Calcium & 2 & 1.1 & 1.62 \\
Calcium & 1 & 1.41 & 1.56 \\
Chloride & 2 & 0.41 & 0.88 \\
Magnesium & 1 & 1.07 & 2.92 \\
Magnesium & 2 & 1.33 & 2.75 \\
Sodium & 2 & -0.08 & -0.78 \\
Sodium & 1 & -0.04 & -0.62 \\
\hline
\end{tabular}

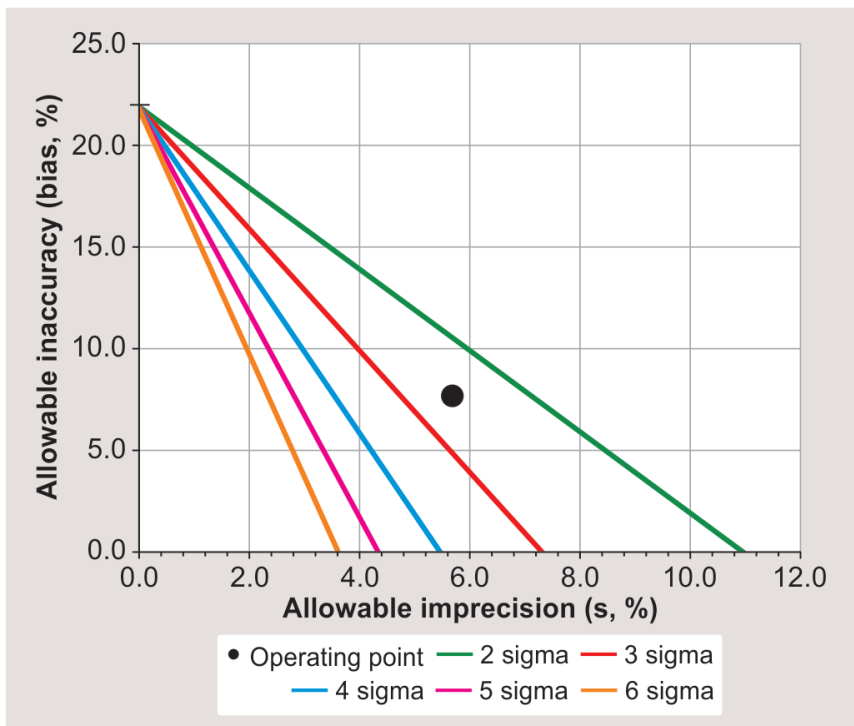

Fig. 2: Method decision chart for AFP L1 before application of suggested rules 


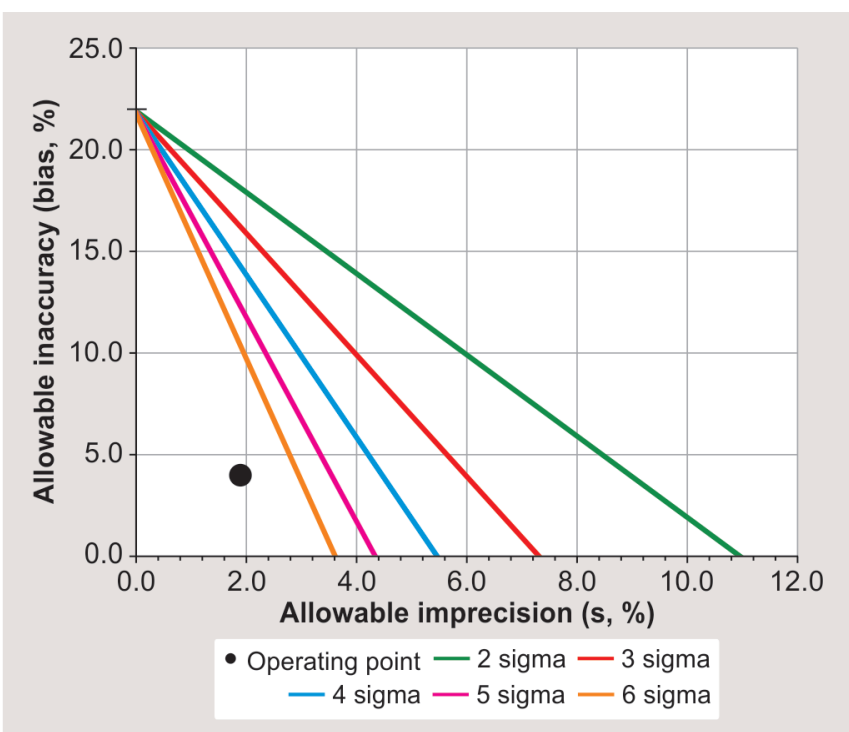

Fig. 3: Method decision chart for AFP L1 after application of suggested rules

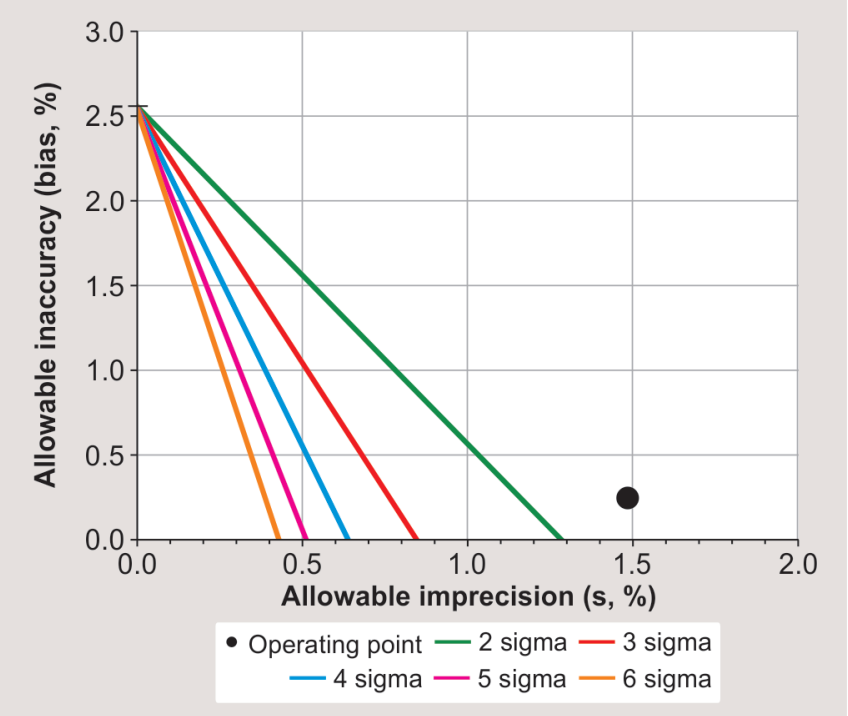

Fig. 5: Method decision chart for calcium L1 after application of suggested rules

performance must be improved before the method can be used for routine diagnostic purposes. ${ }^{7,8}$

In our study, gamma glutamyl transferase has the highest value of sigma of 13.22 at Level 2 of quality control. Total bilirubin was found to have the highest sigma values at both control levels. It was the only analyte having a sigma value of $\geq 6$ for both the levels of QC (7.15 and 9.49 at L1 and L2, respectively). This implies that the analytical method in use is appropriate for detecting both low and high values. The QC strategies that should be implemented in such cases need not be stringent.

Sigma value of $\geq 4$ was observed across all control levels for anti-TPO, CK-MB, potassium, PSA, TSH. According to Westgard sigma rules TM, these analytes are suited for purpose. ${ }^{4}$

We have obtained a sigma value of $\leq 3$ for all levels of calcium, chloride, ferritin, folate, Free T4, magnesium, and sodium. Level 1 of AFP and level 2 of troponin I also had a sigma value of $\leq 3$. Among

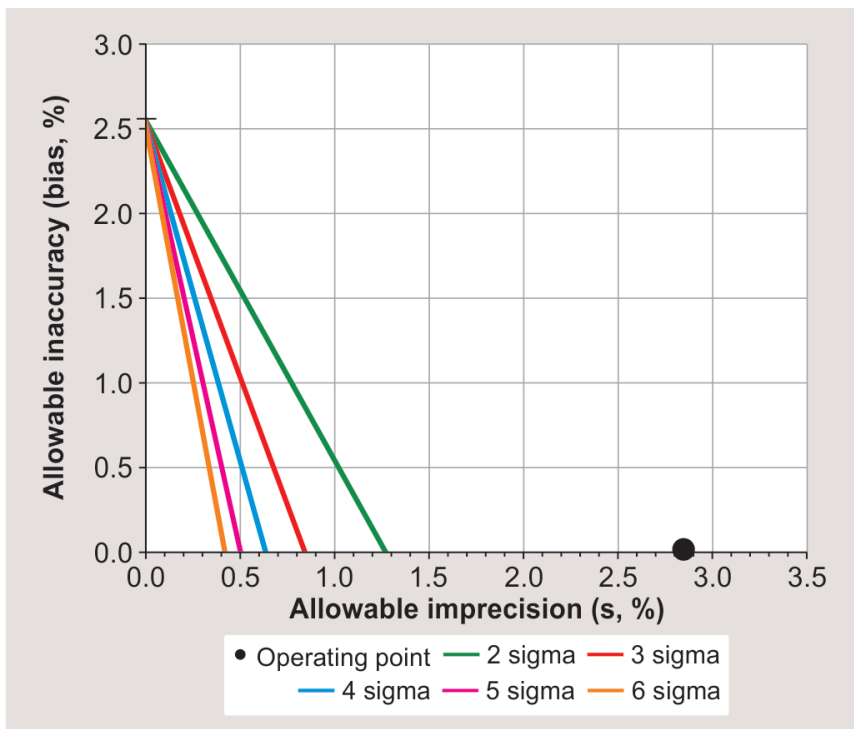

Fig. 4: Method decision chart for calcium L1 before application of suggested rules

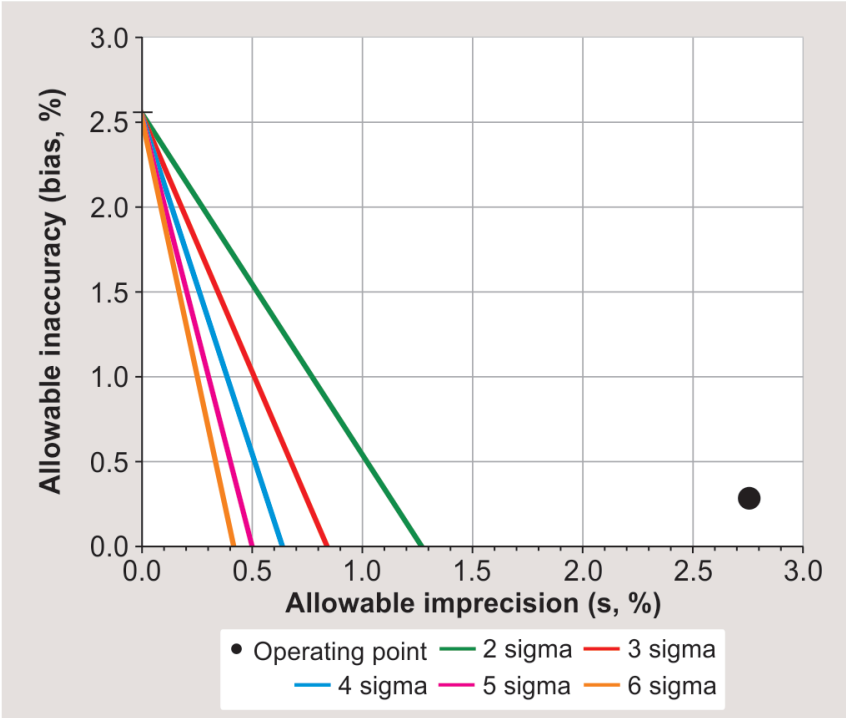

Fig. 6: Method decision chart for calcium L2 before application of suggested rules

these, level 1 of AFP showed a significant improvement in sigma after the application of suggested rules (2.5 to 9.3).

Root cause analysis should be performed for analytes less than three sigma, which did not improve on the application of suggested rules. Selection of appropriate QC procedures for detecting errors can improve test methods to a certain extent. However, it would be a good practice to choose a test method with a six sigma performance to avoid wastage in repeating tests and troubleshooting and to reduce the cost of quality control. Laboratories must also try to control precision through proper training, instrument maintenance, etc. ${ }^{6,11}$

Westgard and Burnett published a paper in 1990 on "Precision requirements for cost-effective operation of analytical process." In this paper, they recommended that laboratories should require four sigma performance for any new method and that even more demanding criteria - five sigma to six sigma-may be necessary 


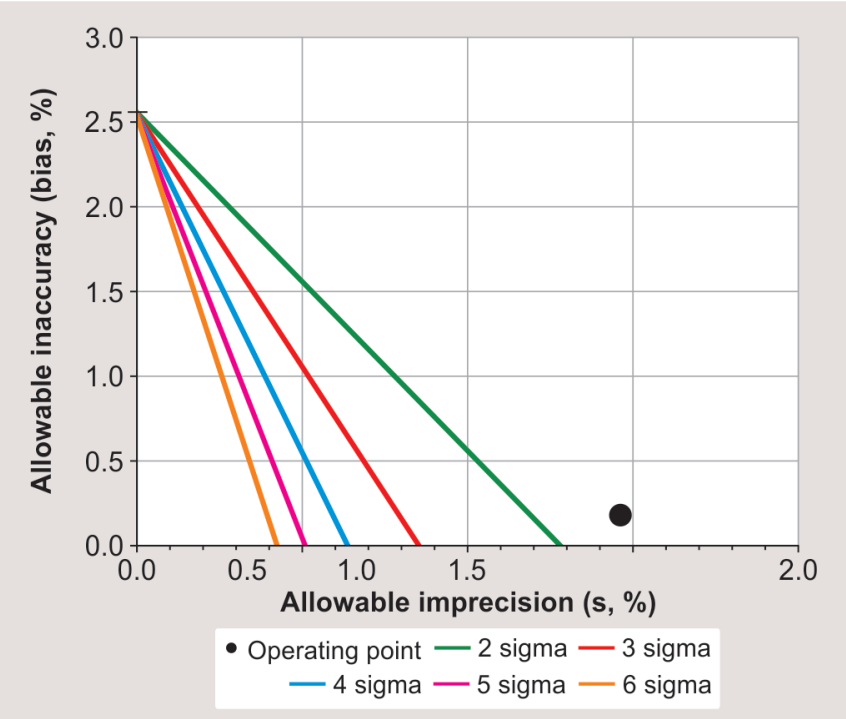

Fig. 7: Method decision chart for calcium L2 after application of suggested rules

for applications where personnel have little training in analytical techniques. ${ }^{6,12}$

The sigma metrics reported here is a snapshot of the analytical performance at the time the data were collected. The performance however can change over time for several reasons (e.g., reagent lot to lot variation).

Sigma metrics need to be monitored periodically to determine if assay quality has been maintained or not.

\section{Conclusion}

Quality goals for the laboratories must be decided appropriately, keeping in mind the inherent random errors and performance capability of analyzers. Sigma metrics is an efficient way to control quality by matching the QC rules to the analytical quality of individual assay which leads to the judicious use of QC.

\section{Acknowledgment}

We acknowledge the support provided by Dr Radhika Krishnaswamy that was much appreciated.

\section{References}

1. Cooper G. Basic Lessons in Laboratory Quality Control. Bio-Rad Laboratories, Inc.; 2008.

2. Cooper G, De Jonge N, Ehrmeyer S. Collective opinion paper on findings of 2010 convocation of experts on laboratory quality. Clin Chem Lab Med 2011;49(5):793-802. DOI: 10.1515/CCLM.2011.149.
Table 6: Analytes for which sigma did not improve after the application of suggested rules

\begin{tabular}{llll}
\hline Analyte & Level & $\begin{array}{l}\text { Sigma before } \\
\text { application of } \\
\text { suggested rules }\end{array}$ & $\begin{array}{l}\text { Sigma after } \\
\text { application of } \\
\text { suggested rules }\end{array}$ \\
\hline Chloride & 1 & 0.4 & 0.13 \\
Ferritin & 3 & 1.75 & 1.33 \\
Ferritin & 2 & 1.85 & 1.79 \\
Ferritin & 1 & 2.91 & 2.88 \\
Folate & 1 & 1.89 & 1.84 \\
Folate & 2 & 2.75 & 2.09 \\
Folate & 3 & 2.81 & 1.93 \\
Free T4 & 1 & 0.55 & 0.32 \\
Free T4 & 3 & 0.78 & 0.77 \\
Free T4 & 2 & 1.08 & 0.86 \\
Troponin I & 2 & 0.59 & -0.58 \\
\hline
\end{tabular}

3. Westgard S. Prioritizing risk analysis quality control Plans based on Sigma-metrics. Clin Lab Med [Internet] 2013;33(1):41-53. DOI: 10.1016/j.cll.2012.11.008.

4. Westgard Sigma Rules [Internet]. [cited 2018 Dec 12]. Available from: https://www.westgard.com/.

5. Perich C, Minchinela J, Ricós C, et al. Biological variation database: Structure and criteria used for generation and update. Clin Chem Lab Med 2015;53(2):299-305. DOI: 10.1515/cclm-2014-0739.

6. Westgard JO. Basic QC. Practices 2010. 312.

7. Nanda SK, Ray L. Quantitative application of sigma metrics in medical biochemistry. J Clin Diagnostic Res 2013;7(12):2689-2691. DOI: 10.7860/JCDR/2013/7292.3700.

8. Singh B, Goswami B, Gupta VK, et al. Application of sigma metrics for the assessment of quality assurance in clinical biochemistry laboratory in India: a pilot study. Indian J Clin Biochem 2011;26(2): 131-135. DOI: 10.1007/s12291-010-0083-1.

9. Kumar BV, Mohan T. Sigma metrics as a tool for evaluating the performance of internal quality control in a clinical chemistry laboratory. J Lab Physicians 2019;10(2):194-199. DOI: 10.4103/JLP. JLP_102_17.

10. Iqbal S, Mustansar T. Application of sigma metrics analysis for the assessment and modification of quality control program in the clinical chemistry laboratory of a tertiary care hospital. Indian J Clin Biochem 2017;32(1):106-109. DOI: 10.1007/s12291-016-0565-x.

11. Hens K, Berth M, Armbruster D, et al. Sigma metrics used to assess analytical quality of clinical chemistry assays: importance of the allowable total error (TEa) target. Clin Chem Lab Med 2014(7): 973-980. DOI: 10.1515/cclm-2013-1090.

12. Westgard JO, Burnett RW. Precision requirements for cost-effective operation of analytical processes. Clin Chem 1990;36(9):1629-1632. DOI: 10.1093/clinchem/36.9.1629. 